\title{
Avaliação Ambiental Estratégica no Brasil: considerações a respeito do papel das agências multilaterais de desenvolvimento
}

\section{Strategic Environmental Assessment in Brazil: debates regarding the role of multilateral development agencies}

\author{
Angela Pellin \\ Bióloga. Docente da Escola Superior de Conservação Ambiental e Sustentabilidade do Instituto de Pesquisas Ecológicas. Doutora em Ciências da \\ Engenharia Ambiental pela Escola de Engenharia de São Carlos da Universidade de São Paulo (USP)
}

\section{Clara Carvalho de Lemos}

Programa de Pós-Graduação em Ciências da Engenharia Ambiental pela Escola de Engenharia de São Carlos da USP

\section{André Tachard}

Programa de Pós-Graduação em Ciências da Engenharia Ambiental pela Escola de Engenharia de São Carlos da USP

\section{Isabel Silva Dutra de Oliveira}

Programa de Pós-Graduação em Ciências da Engenharia Ambiental pela Escola de Engenharia de São Carlos da USP

\section{Marcelo Pereira de Souza}

Professor Titular do Departamento de Biologia da Faculdade de Filosofia, Ciências e Letras de Ribeirão Preto da USP. Pesquisador do Conselho Nacional de Desenvolvimento Científico e Tecnológico (CNPq)

\section{Resumo}

A Avaliação Ambiental Estratégica (AAE) surge como uma ferramenta que fornece oportunidades para a formulação de políticas, planos e programas mais sensíveis às questões ambientais; facilita a integração e coordenação entre vários atores institucionais; e aumenta e fortalece a participação pública. As agências multilaterais de desenvolvimento, como o Banco Interamericano de Desenvolvimento e o Banco Mundial, vêm estimulando a adoção da AAE nos países em desenvolvimento como recomendação ou requisito para aprovação de investimentos e, ainda, por meio de eventos e atividades de capacitação. $\mathrm{O}$ presente trabalho discutiu a situação atual da AAE no Brasil, e o papel que essas agências estão desempenhando na sua implementação, a fim de identificar possíveis melhoras práticas e limitações. Defende-se que a prática da AAE no Brasil seja resultado de um modelo autônomo, baseado nas características e demandas internas.

Palavras-chave: avaliação ambiental estratégica; Banco Mundial; Banco Interamericano de Desenvolvimento.

\section{Abstract}

Strategic Environmental Assessment (SEA) has emerged as a tool that provides opportunities for making policies, plans and programs more sensitive to environmental issues. It can also assist integration and coordination between various institutional actors, and the increasing and strengthening of public participation. Multilateral development agencies such as the Interamerican Development Bank and the World Bank have been encouraging the adoption of SEA in developing countries as a recommendation or requirement for investments approval. This paper presents and discusses the role Multilateral Agencies are actually playing in SEA application in Brazil in order to identify possible best practices and constraints. It is argued that SEA in Brazil should be developed as an autonomous instrument, based on Brazilian institutional context, specific characteristics and internal demands.

Keywords: strategic environmental assessment; World Bank; Inter-American Development Bank. 


\section{Introdução}

Avaliação Ambiental Estratégica (AAE) é o termo usado para definir o processo de avaliação de impacto ambiental de políticas, planos e programas (PPPs) e é frequentemente retratada na literatura como um instrumento de planejamento e de apoio à tomada de decisão (DALAL-CLAYTON; SADLER, 2005; FISCHER, 2007). Dessa forma, a adoção dessa ferramenta permite que a análise e avaliação de alternativas estratégicas sejam realizadas no momento da elaboração das PPPs, o que, segundo Therivel e Partidário (1996), pode contribuir para a consideração das implicações ambientais de PPPs governamentais e realçar seu papel na indução de formas mais sustentáveis de desenvolvimento.

De acordo com Fischer (2007), a AAE possui três significados básicos: 1) processo sistemático de suporte à tomada de decisão, com o intuito de garantir que o meio ambiente e outros aspectos relacionados à sustentabilidade sejam considerados na elaboração de PPPs; 2) instrumento baseado em evidências, com o intuito de fornecer rigor científico à elaboração de PPPs por meio da utilização de uma série de técnicas e métodos de avaliação; e 3) instrumento de apoio à decisão e incentivo ao desenvolvimento sustentável e à governança, por meio do estabelecimento de um foco, por exemplo, nas questões e alternativas a serem consideradas de forma sistemática em diferentes âmbitos e níveis de planejamento.

No final dos anos 1980, diversos países desenvolvidos - principalmente na Europa e nos Estados Unidos da América - já haviam iniciado algumas experiências de aplicação da AAE, mas foi somente a partir do ano 2000 que houve uma expansão de sua prática ao redor do mundo (DALAL-CLAYTON; SADLER, 2005). Muitas dessas experiências resultaram em benefícios, aumentando o conhecimento e a percepção das questões ambientais dentro de processos de tomada de decisão e, em alguns casos, resultando em mudanças relevantes nas ações estratégicas (FISCHER, 1999; THERIVEL, 1998; THERIVEL; PARTIDÁRIO, 1996).

Nos países em desenvolvimento, entretanto, as discussões sobre AAE são mais recentes (DALAL-CLAYTON; SADLER, 2005) e a disseminação do conceito e estímulo à sua implementação tem sido fortemente influenciados pelos países desenvolvidos e por agências multilaterais de desenvolvimento (AMDs). Isso vem acontecendo, a exemplo do que ocorreu com a avaliação de impactos ambientais (AIA) de projetos, principalmente pela incorporação de requisitos ambientais ao processo de financiamento de ações de desenvolvimento econômico. Segundo Rich (1985) tais requisitos são tentativas de evitar os inúmeros e severos problemas ambientais comuns a esses investimentos de grande escala e fluxo de capital.

Para Retief et al (2008), a aplicação da AAE em países em desenvolvimento é considerada de suma importância, já que existe uma grande concentração de atividades econômicas primárias, que são particularmente vulneráveis à degradação ambiental e muitos contam com grandes áreas naturais remanescentes. Além disso, a AAE tem potencial de contribuir para o aumento da transparência no processo de decisão, a ampliação da coordenação entre agências e, em longo prazo, a boa governança (DALAL-CLAYTON; SADLER, 2005).

No Brasil, a AAE também está sendo inserida de forma tardia em relação aos países desenvolvidos (LEMOS, 2007; OLIVEIRA; BURSZTYN, 2001). Tanto o Banco Mundial (BM) quanto o Banco Inter-Americano de Desenvolvimento (BID) têm estimulado sua implementação por meio de eventos, ações de capacitação e como parte dos requisitos para aprovação de seus projetos de investimentos (LEMOS et al, 2007; TACHARD et al, 2007). Pelo exposto, o presente trabalho tem como objetivo apresentar uma contextualização sobre a AAE no Brasil, discutindo o papel do BM e BID na inserção desse instrumento. Para tanto, foi realizada uma revisão teórica sobre o tema, a fim de identificar princípios gerais para aplicação da AAE, algumas experiências existentes no Brasil sob o título de AAE e ainda a influência das AMDs na sua implementação, destacando pontos positivos e limitações desse processo.

\section{Avaliação de impacto ambiental no contexto brasileiro}

A Política Nacional do Meio Ambiente - PNMA (lei n. 6.938/1981) estabelece treze instrumentos a serem utilizados de forma articulada para atingir o objetivo de "preservação, melhoria e recuperação da qualidade ambiental propícia à vida”, bem como "a compatibilização do desenvolvimento econômico-social com a preservação da qualidade do meio ambiente e do equilíbrio ecológico". Todavia, até o momento, nem todos os instrumentos da PNMA foram regulamentados de forma completa, o que vem causando sobrecarga e prejuízos aos demais, e prejudicando o alcance dos objetivos e metas ambientais previstas na política. Um exemplo dessa lacuna é observado com relação à AIA, pois apenas a análise da viabilidade ambiental de projetos (obras ou atividades) encontrase regulamentada, por meio da resolução 001/1986 do Conselho Nacional do Meio Ambiente (Conama), que estabelece definições, responsabilidades, critérios básicos e diretrizes gerais para a elaboração e análise de estudo de impacto ambiental (EIA) e seu respectivo relatório de impacto ambiental (RIMA) - não existindo regulamentação específica para a Avaliação Ambiental Estratégica (AAE) (Figura 1).

Para Milaré (1994), a AIA é apresentada na legislação brasileira em duas dimensões indissociáveis: 1) como instrumento de planejamento e gestão que, no conjunto, tem por objetivo analisar a viabilidade ambiental de PPPs; e 2) como instrumento relacionado ao licenciamento ambiental. 


\section{Avaliação de impacto ambiental no Brasil}

\section{Constituição Federal Brasileira (1988)}

Estabelece que o Poder Público deverá exigir, na forma da lei, estudo prévio de impacto ambiental para instalação de obra ou atividade potencialmente causadora de significativa degradação do meio ambiente

Política Nacional do Meio Ambiente (1981)

Estabelece como seus instrumentos, a avaliação de impactos ambientais e o licenciamento ambiental, dentre outros.

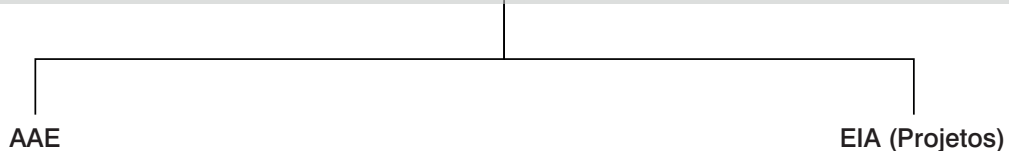

- Não há legislação específica sobre o tema

- Um projeto de lei (PL ${ }^{\circ}$ 2072/2003) foi apresentado e ainda está em discussão desde 2003

AAE: Avaliação Ambiental Estratégica; EIA: Estudo de Impacto Ambiental.

\section{- Resolução Conama 001/1986}

Estabelece critérios básicos e diretrizes gerais para implementação do Estudo de Impacto Ambiental

- Resolução Conama 237/1997

Regulamenta, estabelece critérios, responsabilidades e procedimentos utilizados no licenciamento ambiental.

Estabelece sujeição da emissão de licença ambiental ao estudo de impacto ambiental e respectivo relatório de impacto sobre o meio ambiente empreendimentos e atividades consideradas efetiva ou (EIA/RIMA), para potencialmente causadoras de significativa degradação

Figura 1 - Instrumentos regulatórios e legislativos para a avaliação de impacto ambiental no Brasil.

Na prática, no entanto, a regulamentação da AIA apenas como EIA (projeto) abstraiu sua dimensão de planejamento e avaliação de PPPs e criou um vínculo entre a AIA e o licenciamento. Dessa forma, é verificada uma subutilização da AIA como instrumento de planejamento e a existência de uma expectativa, frequentemente frustrada, de que os EIAs de projetos deem respostas que não lhe competem, o que acaba sobrecarregando-os e colocando-os em descrédito.

Nesse sentido, apesar de existirem várias razões que contribuem para as deficiências na prática da AIA no Brasil, especialmente questões políticas, institucionais e operacionais, seguramente o fato do EIA estar "sobrecarregado" em suas funções contribui para essa situação (OLIVEIRA; SOUZA, 2005). Assim, a adoção da AAE representaria um avanço na implementação da política ambiental, uma vez que lida com questões mais amplas dos pontos específicos tratados no EIA e segundo Egler (2001) poderia suprir as limitações resultantes da atual prática em AIA restrita a projetos.

Vale destacar, no entanto, a desarticulação e lentidão do processo de discussão acerca da institucionalização da AAE no Brasil, em que pese os diferentes e aparentemente conflitantes papéis assumidos pelo Ministério do Meio Ambiente e o Ministério do Planejamento, Orçamento e Gestão. A proposta de lei para regulamentação da AAE está em discussão desde 2003 e o próprio Ministério do Meio Ambiente (MMA), até o momento, não se manifestou sobre o assunto. O Ministério do Planejamento, Orçamento e Gestão desenvolveu e aplicou um procedimento de avaliação integrada de sustentabilidade da carteira de investimentos do país. $\mathrm{Na}$ prática, buscou-se uma simplificação de um processo de AAE, em que a variável ambiental é apenas um componente de um conjunto de questões integradas a serem analisadas, e esse processo ocorreu sem a participação direta do MMA. Ou seja, apesar de algumas iniciativas internas terem sido identificadas, elas ainda ocorrem de maneira desarticulada. Esse fato certamente abre espaço para influência externa, bem como para uma prática questionável e dissociada de princípios ou diretrizes básicos.

\section{Avaliação Ambiental Estratégica no Brasil: atuação do governo e experiências práticas}

As experiências de AAE que o Brasil vem acumulando até o momento têm sido motivadas por dois propósitos distintos: 1) acompanhar a tendência mundial de consideração das questões ambientais em ações estratégicas e atender a necessidade de um novo instrumento ambiental de planejamento, já que o EIA existente é somente para projetos; e 2) atender recomendações ou exigências de elaboração de AAEs como requisitos necessários à aquisição de recursos externos.

No âmbito governamental, as discussões sobre AAE estão, aos poucos, sendo incorporadas, porém ainda de forma localizada e ausente de documentos técnicos oficiais com diretrizes 
e procedimentos específicos. Nesse sentido, um dos principais avanços obtidos até o momento está relacionado à realização de eventos e atividades de capacitação, a partir do ano 2000. Os mais recentes foram: o seminário "Diálogo Técnico sobre AAE e planejamento no Brasil" em 2005 e o "Seminário Latino-Americano sobre AAE", em 2006 que tiveram entre seus propósitos lançar bases para a operacionalização da AAE e contribuir para a formulação de políticas nacionais para sua implementação (TACHARD et al, 2007). Em 2008 foi realizado um seminário para discussão de metodologias de AAE aplicáveis ao Plano Nacional de Logística e Transportes. Um dos objetivos do evento foi fornecer subsídios para elaboração do termo de referência que vai anteceder a contratação do BM para a AAE dos vetores logísticos no Brasil (CENTRAN, 2008).

Decisões legais têm contribuído para estimular a ação governamental, como o acórdão 464/2004 do Tribunal de Contas da União que faz recomendações sobre a utilização do AAE, entre elas: a ampliação da divulgação da AAE e oferta de capacitação sobre o tema; realização de debates sobre a aplicação desse instrumento com a participação de diversos segmentos da sociedade; e análise por parte do governo da conveniência e oportunidade da adoção da AAE no processo de elaboração dos planos plurianuais (PPAs) e de políticas, planos e programas setoriais. Dessa forma, atualmente existem algumas iniciativas como a dos Ministérios do Planejamento, Meio Ambiente e Transportes de articular um grupo de trabalho para discussão e elaboração de um guia com propostas práticas para a AAE no contexto brasileiro (EGLER, 2008), e também a criação de uma gerência dentro do MMA com objetivo de desenvolver metodologias de AAE aplicáveis às áreas de transporte; geração de termoeletricidade, turismo; e biocombustíveis (MMA, 2009).

Apesar de a AAE ainda ser um instrumento em construção no país, algumas experiências práticas demonstram tentativas da inserção da temática ambiental nas políticas setoriais. Um levantamento realizado por Teixeira (2008) apresenta alguns exemplos realizados entre 2002-2007: o Plano Indicativo 2003-2012 da Eletrobrás; o Programa de Desenvolvimento Turístico Sul e o Plano de Desenvolvimento Integrado do Turismo da Costa Norte; o planejamento da exploração e produção de petróleo e gás na Bacia Camumu-Almada; o Complexo Hidrelétrico do Rio Madeira; o Complexo Petroquímico do Rio de Janeiro; o Rodoanel Metropolitano de São Paulo; e o Programa Rodoviário de Minas Gerais.

No entanto, é importante citar que alguns estudos chamados de AAE tratam-se na realidade de EIAs de mega empreendimentos. Como exemplo, pode-se citar a "Avaliação Ambiental Estratégica do Rodoanel Mário Covas” em São Paulo, que segundo Sánchez e Silva-Sánchez (2008), não trata de questões mais estratégicas de uso do solo e planejamento urbano e nem de diferentes alternativas de desenvolvimento para o futuro, e apesar de influenciar a identificação e escolha de rotas alternativas, não influencia na decisão da construção da rodovia em si. Um dos principais problemas, contudo, é que a construção do Rodoanel trata-se de um projeto, e a AAE deveria estar no processo de tomada de decisão em um momento muito anterior a esse, durante a discussão das políticas de transporte mais adequadas para a região.

Outra experiência ocorreu na construção do Gasoduto BolíviaBrasil, no início da década de 1990. Nesse caso, uma AAE foi requerida pelo BID como requisito para concessão do empréstimo e com o intuito de oferecer às instituições financiadoras e executoras do projeto uma visão mais abrangente dos benefícios, impactos e riscos associados à obra. O estudo foi realizado após o governo brasileiro já ter emitido sua licença ambiental prévia e, de acordo com Teixeira (2008), foi dissociada de qualquer processo de planejamento setorial ou regional que eventualmente pudesse se apropriar dos seus resultados e recomendações. Segundo Batmanian (2006), representante do Banco Mundial, a realização da AAE para o Gasoduto visou "incorporar na análise do empreendimento as implicações socioeconômicas e ambientais das transformações induzidas nos setores boliviano e brasileiro, e a sinergia com outros projetos", o que, portanto, ressalta sua característica de AIA de mega projeto.

Recentemente o BID apoiou outro projeto estruturante de duas grandes centrais hidrelétricas na região da Amazônia brasileira (Complexo do Rio Madeira), com objetivo de atender à necessidade de energia que os cenários de crescimento econômico do país demandam. No entanto, no momento da elaboração da AAE, a decisão política inerente ao planejamento setorial de implantar o complexo já estava tomada, e o processo de licenciamento ambiental já estava em andamento. Nesse caso, o estudo

Quadro 1 - Limitações gerais do estudo de Avaliação Ambiental Estratégica (AAE) do Complexo do Rio Madeira.

- É dado destaque para os efeitos de sinergia dos dois empreendimentos com outras questões estruturais na área analisada, o que é considerado um dos papéis dos estudos de impacto ambiental de projetos.

- A análise das políticas, planos e programas incidentes na região foi meramente descritiva.

- Não houve discussão e avaliação de questões realmente estratégicas, anteriores à decisão de construir as usinas. Não há discussão de caráter estratégico a respeito de alternativas à oferta e demanda de energia.

- Caráter reativo do estudo. A análise de cenários está focada em discutir atendimento à demanda crescente de energia do país.

- Destaque excessivo aos impactos positivos do empreendimento, seu papel transformador da dinâmica econômica e no atendimento à demanda por energia.

Fonte: IBAMA, 2005 
surgiu como uma alternativa para avaliar questões que deixaram de ser tratadas nos estudos prévios de impacto ambiental e não há, portanto, discussão de natureza estratégica dos aspectos que determinam a opção por esse empreendimento, e a abordagem é claramente de avaliação ex-post. O Quadro 1 apresenta as principais limitações encontradas na AAE apresentada pelo proponente do empreendimento no Rio Madeira, as usinas hidrelétricas de Jirau e Santo Antônio.

Cabe destacar também que, no caso do Complexo do Rio Madeira, ambos os estudos (EIA e AAE) foram encomendados pelo proponente do empreendimento e apresentados ao órgão licenciador, o IBAMA. A AAE, portanto, está incluída como parte dos documentos técnicos do processo de licenciamento do empreendimento, e foi apresentada em momento posterior à entrega do EIA-RIMA (MINISTÉRIO PÚBLICO DO ESTADO DE RONDÔNIA, 2006).

\section{Análise do papel das agências multilaterais de desenvolvimento na disseminação da AAE}

No Brasil, apesar de alguns esforços do governo, os principais incentivos e estímulos à aplicação da AAE no país são decorrentes dos investimentos de AMDs como o BID e o BM (LEMOS et al., 2007; TACHARD et al., 2007), e essas instituições estão se tornando as principais forças de atuação (driving forces) no processo de discussão, capacitação e fomento de experiências práticas de AAE.

Segundo Killeen (2007), as AMDs têm sido severamente criticadas por não identificar e mitigar os impactos ambientais e sociais associados aos projetos que eles financiam. Visando minimizar esse problema, desde a década de 1980, tanto o BID quanto o BM têm desenvolvido diretrizes para seus investimentos que incluem análises de viabilidade ambiental, porém, apenas mais recentemente estas análises têm alcançado níveis mais estratégicos, cuja uma das ferramentas utilizadas para isso tem sido a AAE.

No Brasil e em diversos outros países em desenvolvimento, essas AMDs têm se destacado no financiamento de políticas de desenvolvimento e inserção de instrumentos de AIA de projetos, ao exigir ou estimular sua adoção durante seus investimentos. Mais recentemente, essas instituições passaram a exigir ou recomendar a incorporação de relatórios de AAE no processo de aprovação de financiamentos de planos e programas de desenvolvimento econômico, o que tem encorajado os países favorecidos à realização de AAE e estimulado discussões, atividades de capacitação e experiências práticas

Conforme Horberry (1985), essas agências têm investido recursos em órgãos ambientais dos países receptores, o que tem contribuído para o aumento do status político das questões ambientais. Além disso, investimentos em estudos e projetos ambientais por órgãos governamentais podem gerar oportunidades para que as questões ambientais ganhem importância maior e sejam levadas em consideração no planejamento e na tomada de decisão. Ainda segundo Horberry (1985), essas ações parecem uma boa oportunidade de demonstrar ao mundo que as agências estão fazendo progressos, tendo em vista a pressão política que sofrem para prestar contas sobre os impactos ambientais de suas operações.

Uma análise da atuação dessas agências permite identificar algumas características, tais como: o enfoque em uma abordagem de avaliação integrada, existência de AAEs com característica em AIA de projetos, e o estímulo à capacitação, as quais serão discutidas a seguir.

\section{Abordagem de avaliação integrada}

A AAE é vista como um instrumento com forte potencial para pôr em prática o conceito de sustentabilidade (DUSIK et al., 2003; FISCHER, 1999). Ainda na década de 1990, quando o termo desenvolvimento sustentável se popularizou, teve início uma discussão sobre a necessidade de ampliação do escopo das AAEs, com a inclusão de questões sociais e econômicas, caracterizando uma abordagem "integrada" (FISCHER; SEATON, 2002). Nesse sentido, uma AAE de PPPs, com características de avaliação integrada, consideraria as questões sociais e ambientais juntamente com seus aspectos econômicos, técnicos, institucionais e financeiros (BANCO MUNDIAL, 2008; KJORVEN; LINDHJEM, 2002). No entanto, o debate a respeito das vantagens e limitações dessa abordagem permanece em aberto, e segundo Scrase e Sheate (2002) a abordagem integrada, longe de encorajar o desenvolvimento sustentável, pode estar meramente promovendo a prevalência de modelos de desenvolvimento dirigidos fundamentalmente por questões econômicas

Em países em desenvolvimento, a abordagem integrada parece ser mais atraente aos governos e agências que financiam o desenvolvimento econômico, pois acomoda e justifica o patrocínio ao crescimento. No Brasil não é diferente, e recentemente o Ministério do Planejamento passou a elaborar e encorajar a adoção de um método baseado na avaliação de sustentabilidade a ser adotado dentro da esfera governamental (EGLER, 2008).

Essa é a abordagem que vem sendo estimulada por AMDs e, nesse sentido, existe a preocupação desse enfoque em priorizar o alcance de metas econômicas e atendimento à necessidade de recursos, desconsiderando a relevância específica da AAE e, assim, utilizar esse instrumento para inserir algumas questões ambientais durante um processo de avaliação, mas sem comprometer os objetivos econômicos que essas instituições defendem e estimulam.

\section{Abordagem de avaliação de projetos}

O BM e o BID elaboram periodicamente documentos contendo as estratégias e os planos para atuação nos países tomadores 
de empréstimos, denominados Country Assistance Strategy (CAS) e Country Strategies (CS), respectivamente, ambos contendo orientações referentes a reformas econômicas ou ajustes estruturais e projetos de investimentos, tais como: infraestrutura, agricultura, meioambiente, reforma agrária, saúde e educação.

Dessa forma, apesar da tentativa de integração de considerações ambientais em fases de planejamento estratégico, o que se tem constatado é que a AAE é exigida pelos bancos apenas em uma etapa posterior, quando as principais estratégias e projetos para o plano de investimento do país já foram definidas. Segundo Kjörven e Lindhjem (2002), a maioria das AAEs do BM é realizada como parte de programas de empréstimos para financiamento de subprojetos, e raramente realizada durante as discussões mais precoces, na definição do escopo e objetivos de um plano ou programa. Assim, a decisão sobre os projetos resultantes dos planos e programas financiados por essas instituições é tomada previamente por seus representantes, com anuências dos governos locais e dessa forma, as AAEs tornam-se mais instrumentos políticos, dissociadas do processo de planejamento, e elaboradas para cumprir exigências formais. Dentro desse modelo, a AAE é solicitada por essas instituições simplesmente como requisito para aprovação ou não da concessão de financiamentos para determinados programas de investimento e é realizada muito tarde, quando já não é possível considerar seus resultados no processo de tomada de decisão (Figura 2).

Como resultado desse modelo de atuação, algumas experiências denominadas AAE e elaboradas como parte de requisitos para concessão de empréstimos por AMDs tem se tratado, na verdade, de estudos de impacto ambiental de mega empreendimentos. Essas práticas têm atribuído a esses estudos um caráter estratégico do qual não estão revestidos e têm contribuído para a disseminação de um conceito equivocado da AAE.

\section{Enfoque em atividades de capacitação}

Segundo Annandale et al. (2001) uma influência positiva das AMDs está relacionada ao desenvolvimento de inúmeros projetos de assistência técnica, a fim de fornecer auxílio no fortalecimento institucional da AAE aos países mutuários. No Brasil, têm sido realizados eventos e cursos de capacitação em AAE, no entanto, é possível observar que estes estão restritos a alguns nichos da esfera federal e a alguns poucos representantes dos Estados, e não há um esforço para abranger todas as esferas da sociedade interessada, o que coloca em dúvida a legitimidade e a representatividade desse processo.

Outra característica é que frequentemente essas atividades de capacitação vêm acompanhadas da elaboração de guias e diretrizes para implementação da AAE, como é o caso da chamada Draft Guidance for SEA, elaborada para subsidiar a aplicação da AAE em iniciativas apoiadas pelo BID na América Latina e Caribe (IADB, 2004). A utilização desses guias pode representar um problema na medida em que esses documentos são desenvolvidos geralmente por consultores externos contratados pelas agências internacionais que, por sua vez, desconhecem as necessidades, problemas e limitações específicas das diferentes regiões onde atuam. Além disso, essas metodologias prontas podem resultar na adoção de considerações ambientais simplesmente como uma decisão populista, sem o envolvimento das esferas regionais e locais, sem participação pública e mesmo sem clara percepção de avaliação ambiental por órgãos governamentais (ALSHUWAIKHAT, 2005).

Dessa forma, deve-se questionar se um programa de treinamento com uma estrutura rígida e pronta poderá surtir efeitos positivos em longo prazo, no sentido de estimular experiências voltadas às necessidades locais. Além disso, a atuação dessas agências deveria se basear mais no fomento às discussões internas e no

* Gasoduto Bolívia-Brasil

* Complexo de Rio Madeira

* Rodoanel São Paulo

AAE: Avaliação Ambiental Estratégica.

Figura 2 - Modelo genérico do ciclo de um programa de AMDs.

Adaptado de Annandale et al. (2001).

Country Assistance Strategy (CAS) e Country Strategy

$\mathrm{AAE}$

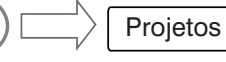

$\longrightarrow \begin{aligned} & \text { Planos dos países mutuários } \\ & \text { e doadores }\end{aligned}$




desenvolvimento de modelos baseados no conhecimento e experiência institucionais brasileiros, e menos na tentativa de imposição de um modelo externo.

\section{Aspectos políticos e institucionais da atuação das AMDs}

De acordo com as diretrizes do BM (Bank Procedure 4.01), quando é detectada a necessidade de estudos ambientais para aprovação das operações do banco, este auxiliaria o mutuário na elaboração de termos de referência para o desenvolvimento do estudo e seu relatório, o qual seria posteriormente apresentado ao banco e avaliado. Nesse caso, quando detectada a necessidade de estudos mais estratégicos, o BM poderia sugerir uma AAE, já que segundo a Política Operacional 4.01 a realização de estudos dessa natureza não seria uma exigência, mas sim recomendação. Também vale destacar que atualmente o BM atua com um enfoque denominado learning by doing ou aprenda fazendo (KJORVEN; LINDHJEM, 2002). Como consequência dessa abordagem, estudos com procedimentos e métodos completamente diferentes têm se apresentado sob a denominação de AAE, porém sem necessariamente apresentar condições mínimas para tal.

Já para o BID, quando é identificada a necessidade, a aprovação de crédito está condicionada à apresentação de um relatório de AAE pelo mutuário (IADB, 2004). Nesse caso, a AAE torna-se uma condicionante para aprovação de financiamentos, perdendo sua função de efetivamente influenciar a tomada de decisão em situações estratégicas, tendo como variável a questão ambiental. Dessa forma, esse modelo não explicita o papel da AAE, tornando duvidoso se esta é utilizada para subsidiar a tomada de decisão ou para justificar decisões já tomadas. Além disso, a aprovação de financiamentos condicionados à apresentação de um relatório de AAE pode funcionar como um fator de pressão externo sobre as agências ambientais brasileiras em favor do licenciamento de mega projetos, além de contribuir para a disseminação de um conceito equivocado do instrumento.

Analisando esse contexto, Santana (2006) é bastante crítico, destacando que muitas das ações de cooperação e transferência de conhecimentos aos países mutuários da América Latina são fortes indicadores do interesse dessas instituições em direcionar estas sociedades política, social e economicamente. O autor também destaca que tanto para o BM quanto para o BID, a definição dos projetos - que decidem se os países estão aptos a receber apoio técnico e financeiro - dependem, quase totalmente, da política econômica em curso, que deve estar adequada aos interesses financeiros desses bancos.

No Brasil, um caso recente pode exemplificar melhor a tentativa de interferência dessas AMDs nas políticas governamentais. Em 2008 foi publicado pelo BM um relatório intitulado
"Licenciamento ambiental de empreendimentos hidrelétricos no Brasil", com objetivo de contribuir com o debate em torno do tema (BANCO MUNDIAL, 2008). Esse documento defende uma reforma no sistema de licenciamento ambiental brasileiro e sugere que a emissão de licenças ambientais deveria ser feita para um grupo de projetos, baseada num plano que contenha os elementos principais de uma AAE. A AIA de projetos só seria necessária para obtenção da licença de instalação e deveria ser focada na prevenção e mitigação de possíveis impactos ambientais, mas sem considerar questões mais amplas acerca da viabilidade ambiental do projeto. Com isso, a AIA de projetos perderia a função prevista na legislação brasileira de considerar e avaliar alternativas locacionais para cada projeto individualmente, a qual seria transferida para um instrumento de avaliação integrada, a AAE (BANCO MUNDIAL, 2008).

Dessa forma, é possível notar que o discurso do BM está focado no "obstáculo" do licenciamento ambiental, "atraso" dos processos e seus custos. Além disso, a recomendação do BM é equivocada ao sugerir que a AAE substitua a AIA de projetos prevista na legislação ambiental brasileira, já que ambas têm propósitos e abordagens complementares e diversas. Essa posição do BM é, segundo Garzon (2008), uma estratégia explícita para desmontar as regulamentações ambientais brasileiras, que sugere ainda que a maioria das mensagens e recomendações propostas nos estudos e relatórios técnicos apresentados pelo BM são intromissões travestidas de "recomendação técnica" para as questões institucionais brasileiras (GARZON, 2008)

As recomendações feitas pelo BM foram alvo de duras críticas do MMA, que destacou a parcialidade, o enfoque tendencioso e a visão restrita do documento a respeito das questões que envolvem a PNMA e um de seus principais instrumentos, o licenciamento ambiental. O ministério entende que a AAE não deve substituir o EIA de projetos e defende que a sua adoção no Brasil ainda carece de mais debate no âmbito do governo para estabelecimento e entendimento sobre seu universo de aplicação e estratégias de internalização nos diferentes níveis de governo (MMA, 2008).

Analisando esse exemplo, é possível observar que se por um lado essas agências tornaram-se líderes na inserção de instrumentos de AIA no país e referências em práticas de AAE, por outro, é negativa sua postura ao desconsiderar a estrutura institucional e legal, assim como as normas que regem a AIA no país atualmente. Dessa forma, estimular o uso de instrumentos inexistentes no arcabouço legal brasileiro e à revelia das instituições existentes, pode levar ao descrédito e enfraquecimento destas (OLIVEIRA, 2008) e pode-se configurar uma tentativa de modificar o sistema legal e institucional brasileiro para que seja possível acomodar o modelo de AAE estimulado pelas AMDs.

Recentemente, o BM declarou que sua política de assistência ao Brasil será baseada nos objetivos e prioridades estabelecidos nos 
Planos Plurianuais (PPAs) do Governo Federal (BANCO MUNDIAL, 2006), que representam a estratégia de desenvolvimento econômico do país num horizonte de quatro anos. Isso, aliado à tendência do governo pela realização da AAE para os PPAs deve ser visto com ressalvas, já que estes não contemplam a efetiva participação da sociedade em sua elaboração e têm com principal foco a identificação de metas estritamente econômicas estabelecidas num contexto político específico e para um período de quatro anos. Por isso, é questionável se a melhor opção seria estimular a aplicação da AAE para um plano com essas características, ou se o correto seria a inserção da AAE em um contexto de avaliação de uma política de desenvolvimento para o país, em que as metas econômicas do PPA seriam apenas mais uma variável no processo decisório. Nesse caso, o objetivo central seria a integração e o diálogo entre planos com diferentes enfoques.

\section{Conclusão}

Atualmente, não existe arcabouço legal nem referências conceituais bem estabelecidas para adoção da AAE no Brasil, estando a discussão da inserção desse instrumento ainda restrita. Nesse sentido, é necessário que os esforços para inserção desse instrumento estejam menos baseados na imposição de um modelo externo e muito mais no fomento às discussões internas e nas experiências institucionais brasileiras.

Notadamente, o BID e o BM têm influenciado e direcionado a prática de AAE no Brasil sob a ótica da abordagem integrada e de acordo com modelos e diretrizes fornecidos por essas instituições.

É necessário destacar que a AAE, da maneira como é incentivada por essas agências, possui várias limitações, destacando-se o caráter pouco estratégico, já que é utilizada em uma etapa posterior ao processo decisório. A prática mostra que os estudos de impacto ambiental de mega projetos financiados por essas agências são apresentados como AAE, com o intuito de apresentar uma visão mais abrangente dos benefícios, impactos e riscos sociais e ambientais de projetos individuais, e não de PPPs. Não há, portanto, espaço para discussão estratégica nesses estudos, já que as decisões com esse caráter já foram tomadas anteriormente.
Outra questão que vale ser ressaltada é que a pressão externa para inserção da AAE no Brasil, estimulada e liderada por AMDs para atendimento de uma demanda prioritariamente econômica, não invalida seu caráter inovador e mobilizador; no entanto, pode desvirtuar os propósitos do instrumento. Sendo assim, esse processo não pode prescindir de uma análise mais profunda e crítica sobre seus desdobramentos e consequências práticas sobre o processo político e institucional de planejamento brasileiro.

A influência que as AMDs exercem sobre a própria política ambiental brasileira tem se dado tanto pelo financiamento direto de programas e projetos setoriais e de infraestrutura, quanto por meio de atividades de assessoria, assistência técnica, capacitações e inserção de conceitos. Além disso, instrumentos de AIA de projetos ou PPPs têm sido utilizados como condicionante para aprovação de empréstimo. Se, por um lado, isso traz um avanço sobre certos temas como a própria AIA, por outro surgem preocupações sobre o nível de interferência aceitável dessas instituições em assuntos que deveriam ser amadurecidos internamente com o intuito de se alcançar consensos. No caso da AAE, percebe-se que essa interferência tem contribuído pouco no desenvolvimento de modelos próprios, que considerem as características, demandas, experiências, forças e limitações do país, e muitas vezes os estudos chamados de "AAE" são utilizados como instrumento de pressão por parte dos organismos financiadores em favor da aprovação de projetos polêmicos.

Dessa forma, é preciso que a discussão sobre as metodologias, abordagens e maneiras de aplicação da AAE seja ampliada no país, e que o governo brasileiro assuma um papel mais proativo na discussão e estabelecimento de consensos sobre o tema. Além disso, é necessário o fortalecimento da participação da sociedade no processo de discussão e avaliação desses modelos de AAE, para que a prática no Brasil reflita um modelo autônomo, baseado nas características e demandas internas, complementando de forma positiva (e não suprimindo) os instrumentos já existentes da Política Nacional do Meio Ambiente. Assim, o país poderá se tornar protagonista desse processo e as agências multilaterais também poderão agregar suas contribuições, porém assumindo o papel complementar que lhes compete.

\section{Referências}

ALSHUWAIKHAT, H.M. Strategic environmental assessment can help solve environmental impact assessment failures in developing countries. Environmental Impact Assessment Review, v. 25, n. 4, p. 307-317, 2005.

ANNANDALE, D. et al. The potential role of strategic environmental assessment in the activities of multi-lateral development banks. Environmental Impact Assessment Review. v. 21, n. 5, p. 407-429, 2001
BANCO MUNDIAL. Licenciamento ambiental de empreendimentos hidrelétricos no Brasil: uma contribuição para o debate. 2008. 35p. Disponível em: <http://74.125.47.132/search?q=cache:P3TWvBIx0FoJ :siteresources.worldbank.org/INTLACBRAZILINPOR/Resources/Brazil_ licenciamento_SintesePortugueseMarch2008.pdf+Licenciamento+am biental + de+empreendimentos + hidrel\%C3\%A9tricos + no +Brasil\&cd = $3 \& \mathrm{hl}=\mathrm{pt}-\mathrm{BR} \& \mathrm{ct}=\mathrm{clnk} \& \mathrm{gl}=\mathrm{br}>$. Acesso em: 12 abr. 2009. 
. Relatório de progresso: estratégia de assistência ao Brasil. 2006. Disponível em: <http://www.bancomundial.org.br/index.php/content/ view_folder/2683. html>. Acesso em: 10 nov. 2007

BATMANIAN, G. Avaliação Ambiental Estratégica em instituições financeiras multilaterais. In: Seminário Latino Americano de Avaliação Ambiental Estratégica. 2006. Disponível em: <www.mma.gov.br>. Acesso em: 12 abr. 2009.

CENTRO DE EXCELÊNCIA EM ENGENHARIA DE TRANSPORTES (CENTRAN). Ministério dos Transportes realiza seminário para discutir avaliação ambiental estratégica. 2008. Disponível em: <http://www. centran.eb.br/clipping/2008/clipping_siteMT_251108.pdf > . Acesso em: 03 abr. 2009.

DALAL-CLAYTON, B.; SADLER, B. Strategic environmental assessment: a sourcebook and reference guide to international experience. London. Earthscan. 2005. $470 \mathrm{p}$

DUSIK, J. et al. Benefits of a Strategic Environmental Assessment. REC/ UNDP. 2003. Disponível em: <http://europeandcis.undp.org/home/ show/62B6F19C-F203-1EE9-B747F5CFD2FCBD43>. Acesso em: 15 abr. 2009

EGLER, P.C.G. Elaboração de um guia de AAE para o Governo Federal. 2008. Disponível em:< http://www.iea.usp.br/iea/online/midiateca/ ambiente/index.html> . Acesso em: 15 jul. 2009.

Perspectivas de uso no Brasil do processo de avaliação ambiental estratégica. Parcerias estratégicas, n. 11, p. 175-190, jun. 2001.

FISCHER, T.B. The theory and practice of strategic environmental assessment: towards a more systematic approach. UK/USA: Earthscan. 2007. $186 \mathrm{p}$.

Benefits arising from SEA application - a comparative review of North West England, Noord-Holland and Brandenburg-Berlin. Environmental Impact Assessment Review, v. 19 n. 2 p. 143-173, 1999.

FISCHER, T.B.; SEATON, K. Strategic environmental assessment: effective planning instrument or lost concept? Planning Practice \& Research, v. 17 n. 1 p. 31-44. 2002.

GARZON, L.F.N. Bird "sugere" licenciamento submisso aos investidores, 2008. Disponível em: <http://www.oeco.com.br/convidados/64colunistas-convidados/16817-oeco_26918>. Acesso em: 20 mar. 2009.

HORBERRY, J. International organization and EIA in developing countries. Environmental Impact Assessment Review. v. 5 n. 3 p. 207-222, 1985.

INTER-AMERICAN DEVELOPMENT BANK (IADB). Conditional credit line for investment projects (CCLIP). Environmental procedures and SEA guidance, 2004. Disponível em: <http://idbdocs.iadb.org/ wsdocs/getdocument.aspx?docnum $=1448839>$. Acesso em: $13 \mathrm{dez}$. 2008.

Instituto Brasileiro do Meio Ambiente e dos Recursos Naturais Renováveis (IBAMA). Complexo do Rio Madeira - UHE Santo Antonio e UHE Jirau: documentos do processo, 2005. Disponível em:< http:// www.ibama.gov.br/licenciamento/index.php>. Acesso em 06 out. 2010.

KILLEEN, T.J. Avaliação Ambiental e Social e Mitigação de Impactos. In Uma tempestade perfeita na Amazonia: desenvolvimento e conservação no contexto da Iniciativa pela Integração da Infra-Estrutura Regional Su Americana (IIRSA). Advances in Applied Biodiversity Science, n. 7, p. 73-77, 2007

KJÖRVEN, O.; LINDHJEM, H. Strategic environmental assessment in World Bank operations: experience to date - future potential. Oslo, Norway. ECON - Centre for Economic Analysis, 97 p. 2002.

LEMOS, C.C. Avaliação ambiental estratégica como instrumento de planejamento do turismo. Dissertação (Mestrado). 185p. Escola de Engenharia de São Carlos, Universidade de São Paulo, São Carlos, São Paulo, 2007.

LEMOS, C.C.; OKUMURA, D.T.; MASSARO, F.C. O BID e a avaliação ambiental estratégica no Brasil. In: SANEAMENTO AMBIENTAL: COMPROMISSO OU DISCURSO? Anais... Associação Brasileira de Engenharia Sanitária e Ambiental. Belo Horizonte, Minas Gerais, 2007. CD-ROM.

MILARÉ, E. Estudo prévio de impacto no Brasil. In: AB'SABER, A.N.; MÜLLER-PLATEBERG, C. (Org.) Previsão de impactos. São Paulo: USP 1994. p. $51-80$.

MINISTÉRIO DO MEIO AMBIENTE (MMA). Manifestação sobre o Estudo elaborado pelo Banco Mundial. PARECER nº 001/2008. GAIA/DLAA/ SMCQ/MMA. 2008.

Instrumentos de avaliação ambiental. Departamento de Licenciamento e Avaliação Ambiental, 2009. Disponível em:< http:// www.mma.gov.br/sitio/index.php?ido = conteudo. monta\&idEstrutura $=1$ 39\&idMenu=7323\&idConteudo=7258 > . Acesso em: 03 abr. 2009.

MINISTÉRIO PÚBLICO DO ESTADO DE RONDÔNIA. Relatório de análise do conteúdo dos estudos de impacto ambiental (EIA) e do relatório de impacto ambiental (RIMA) dos aproveitamentos hidrelétricos de Santo Antonio e Jirau, no rio Madeira, Estado de Rondônia. Cobrape, 2006.

OLIVEIRA, I.S.D. Alternativas para a implementação da avaliação ambiental estratégica no Brasil. Tese (Doutorado). 191p. Escola de Engenharia de São Carlos, Universidade de São Paulo, São Carlos, São Paulo, 2008.

OLIVEIRA, A.A., BURSZTYN, M. Avaliação de impacto ambiental de políticas públicas. Revista Internacional de Desenvolvimento Local, v. 2, n.3, p. 45-56, 2001

OLIVEIRA, I.S.D.; SOUZA. M.P. A contribuição do zoneamento ambiental para o estudo de impacto ambiental. In: ESPÍNDOLA, E.V.G.; WENDLAND, E. (Orgs.). PPG-SEA: trajetórias e perspectivas de um curso multidisciplinar. São Carlos: RiMa, 2005. p. 137-154.

RETIEF, F.; JONES, C.; JAY, S. The emperor's new clothes - reflections on strategic environmental assessment (SEA) practice in South Africa. Environmental Impact Assessment Review, v. 28, n. 7, p. 504-514, 2008. 
$\mathrm{RICH}, \mathrm{B} . \mathrm{M}$. Multi-lateral development Banks: their role in destroying the global environment. The Ecologist, v.15 n. 1/2, p.56-68, 1985.

SÁNCHEZ, L.E.; SILVA-SÁNCHEZ, S.S. Tiering strategic environmental assessment and project environmental impact assessment in highway planning in São Paulo, Brazil. Environmental Impact Assessment Review, v. 28, n. 7, p. 515-522, 2008.

SANTANA, J.V. Banco Interamericano de Desenvolvimento e política urbana no município de Belém: tensões e compatibilidades no modelo de gestão de cidades e no discurso da participação social. Tese (Doutorado). 321 p. Programa de Pós-Graduação em Serviço Social da Escola de Serviço Social da Universidade Federal do Rio de Janeiro. Rio de Janeiro, 2006

SCRASE, J.I.; SHEATE, W.R. Integration and integrated approaches to assessment: what do the mean for the environment? Journal of Environmental Policy \& Planning, v. 4, p. 275-294. 2002.
TACHARD, A.L.; PELLIN, A.; SOUZA, M.P. O papel do Banco Mundial na inserção da avaliação ambiental estratégica no Brasil. In: SANEAMENTO AMBIENTAL: COMPROMISSO OU DISCURSO? Anais... Associação Brasileira de Engenharia Sanitária e Ambiental. Belo Horizonte, Minas Gerais, 2007.

TEIXEIRA, I.M.V. O uso da avaliação ambientalestratégica no planejamento da oferta de blocos para exploração e produção de petróleo e gás no Brasil: uma proposta. Tese. 308 p. COPPE. UFRJ. Rio de Janeiro, 2008

THERIVEL, R. Strategic environmental assessment of development plans in Great Britain. Environmental Impact Assessment Review, v. 18 n. 1, p. 39-57, 1998.

THERIVEL, R.; PARTIDÁRIO, M.R. The practice of strategic environmental assessment. London: Earthscan, 1996 